\section{Eruptions of Bulusan Volcano since November 2010}

\section{Mitsuru Okuno*, Eduardo Laguerta ${ }^{* *}$, Perla Delos Reyes ${ }^{* *}$, Ma. Antonia Bornas ${ }^{* *}$, Ma. Hannah Mirabueno**, Ma. Carmencita Arpa ${ }^{* *}$, Ericson Bariso **, \\ Renato Solidum Jr. ${ }^{* *}$, Sachihiro Taguchi*, Masayuki Torii ${ }^{* * *}$ and Tetsuo Kobayashi ${ }^{* * * *}$}

Received October 17, 2011. Accepted October 19, 2011.

Faculty of Science, Fukuoka University, Fukuoka 814-0180, Japan.

** Philippine Institute of Volcanology and Seismology (PHIVOLCS), Quezon City, Philippines.

**** Kumamoto Gakuen University, Kumamoto 862-8680, Japan.

***** Graduate School of Science and Engineering, Kagoshima University, 890-0065, Japan.

Corresponding author; M. Okuno, okuno@fukuoka-u.ac.jp

Bulusan Volcano in the Province of Sorsogon, southern Luzon, is one of the 23 active volcanoes in Philippines (Fig. 1; PHIVOLCS, 2002). Intermittent phreatic eruptions occurred starting November 6 , 2010 (Fig. 2). On November 9, a part of the eruption column collapsed and elutriation clouds drifted down slope (Fig. 3). On February 21, 2011, another phreatic eruption produced a 3-km ash column (Fig. 4). Essential material is not recognized in the eruptive products. Gypsum is detected in aggregated ash by XRD analysis (Fig. 5). Presence of this mineral may be caused by interaction between fine ash and volcanic gas (e.g., $\mathrm{SO}_{2}$ and $\mathrm{H}_{2} \mathrm{O}$ ). Such detailed observation of eruption column behaviour and its constitutions are important for highresolution volcanic geology.
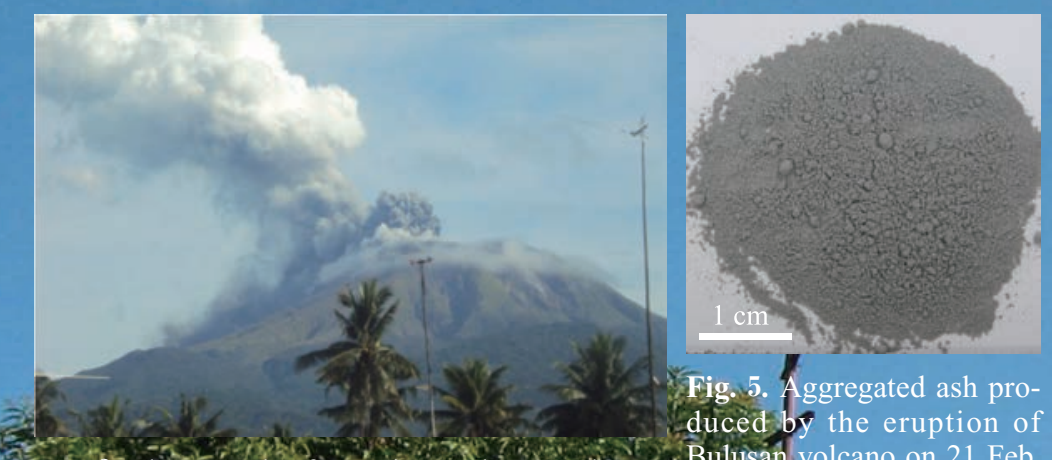
duced by the eruption of Fig. 2. photograph of evupting Bulusan-volcano, Bulusan volcano on 21 Feb. viewed from the south on 6 Nov. $2010^{*}$ (photo-20110 graph by Maria Eliñor Mgnacio)

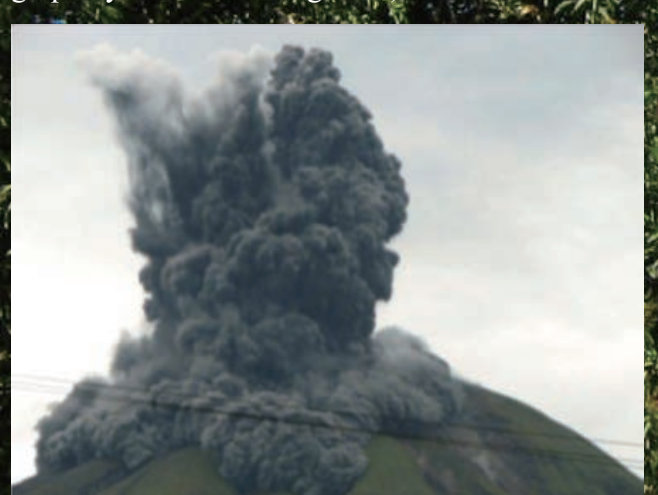

Fig. 3. Photograph of erupting Bullusan oolcano, viewed from Irosin Town proper (from the south) on 9 Nov. 2010 (photograph by Jovic Evasco).

Acknowledgement: We would like to extend our appreciation to Mr. Allan Loza for sharing his collection of photographs of the November 2010 to February 2011 phreatic eruptions of Bulusan Volcano. This study was partly supported by a Grant-in-Aid for Scientific Research from JSPS (No.21401005) and a budget from PHIVOLCS-DOST.

\section{Reference}

PHIVOLCS, 2002. Volcanoes of the Philippines. Department of Science and Technology (DOST), Quezon City, Philippine, 41p.

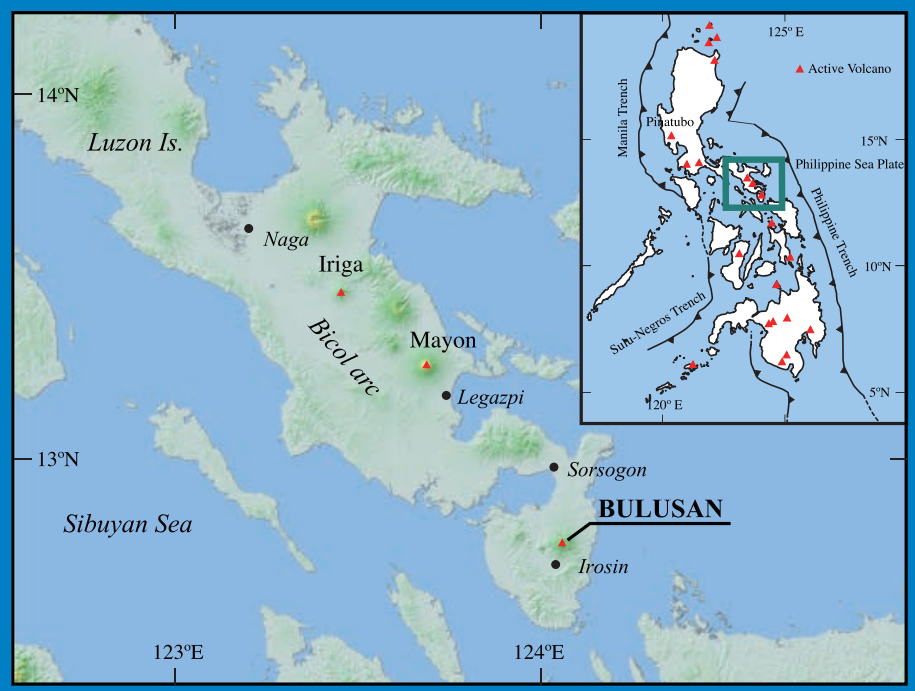

Fig. 1. Index maps of Bulusan volcano. The topographic map was compiled using the program KASHMIR from SRTM-3 data.

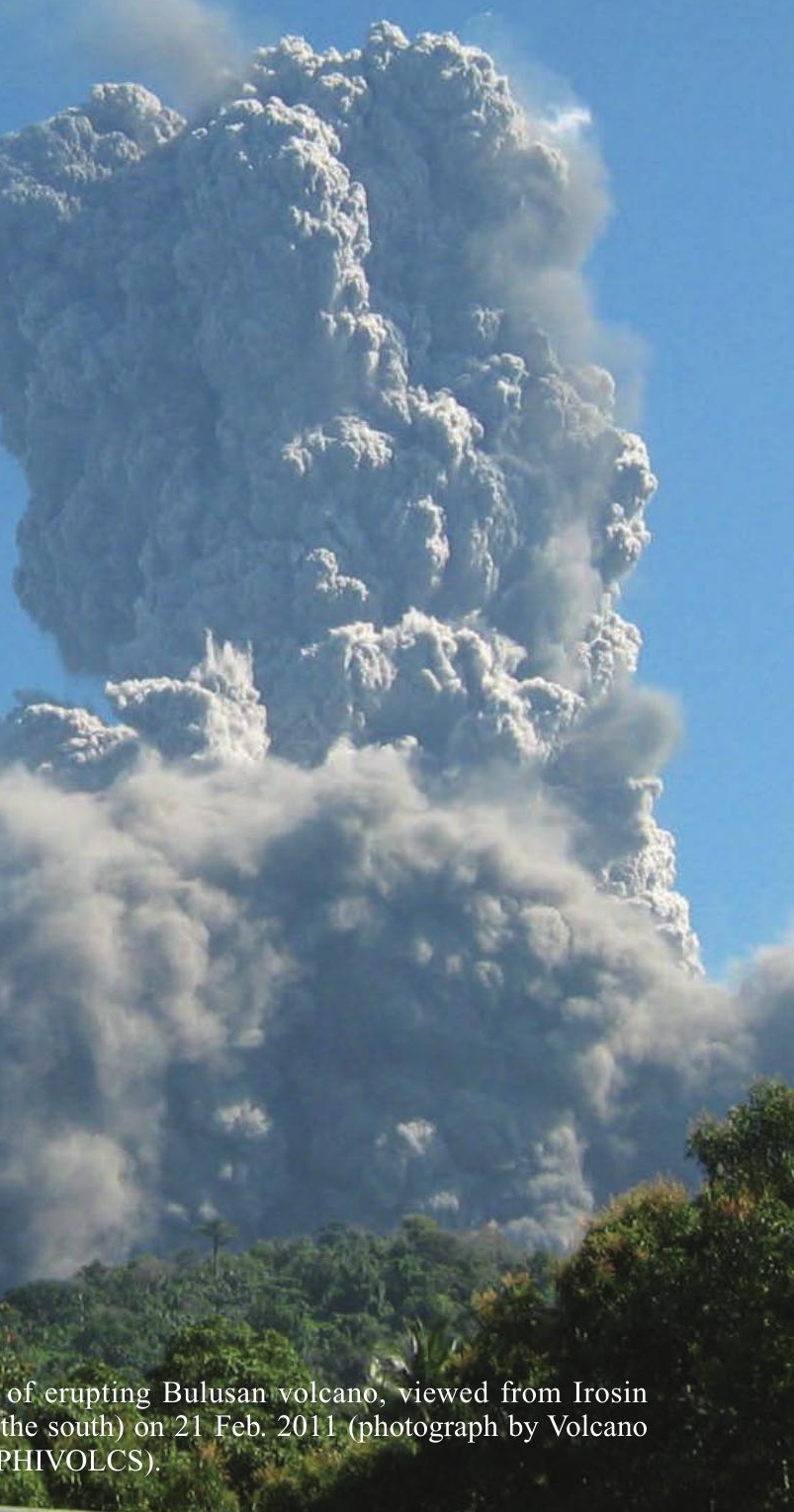

